\title{
Assessing stream restoration works in the southern Macquarie Marshes using hydrodynamic modeling
}

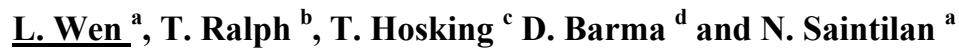 \\ ${ }^{a}$ Waters Wetlands and Coastal Science, NSW Office of Environment and Heritage \\ ${ }^{b}$ Department of Environment and Geography, Macquarie University, NSW 2109 Australia \\ ${ }^{c}$ Regional Operations, NSW Office of Environment and Heritage \\ ${ }^{d}$ Barma Water Resources, Baulkham Hills Sydney NSW Australia 2153 \\ Email:Li.Wen@environment.nsw.gov.au
}

\begin{abstract}
The Macquarie Marshes are an extensive wetland system located in central New South Wales within the lower Macquarie Catchment, representing one of the largest semi-permanent wetlands in southeastern Australia. The Marshes are one of most biologically diverse wetland systems in the Murray Darling Basin, and support some of the largest waterbird breeding events in Australia. A number of studies have demonstrated the critical role of inundation in maintaining the ecological values of the Marshes. The inundation extent, duration and depth of the core wetlands in the Marshes are variable over long and short time-scales, related to geomorphology and flow variability in the Macquarie River.
\end{abstract}

Processes of sedimentation and erosion underlie channel changes in the Marshes and have created a range of landforms with distinct characteristics and spatial distribution. As channels change and move on the floodplain, flooding and sedimentation patterns change and the wetlands respond by relocating, expanding and contracting. The streams and wetlands of the southern part of the Macquarie Marshes have been associated with notable hydrological and geomorphic changes over recent history including channel erosion, changing flow paths and reductions in wetland inundation. Some wetlands have been partly or wholly abandoned by the modern streams (e.g. Macquarie Terminus Marsh and Willie Marsh), while ecologically important wetlands have also developed and changed over time (e.g. Willancorah Swamp). In addition to natural fluvial landforms, there are many anthropogenic features (e.g. roads, levee banks, regulators and channels) that modify the natural landscape and influence flow in the system.

While channel change over time is a significant factor for wetland conservation, the impacts of channel change and potential intervention scenarios have never been assessed at the wetland system or sub-system scale in the South Marshes. In this study, we built a 1D/2D coupled hydrodynamic model (MIKE FLOOD) at fine spatial resolution $(30 \mathrm{~m})$ for the South Marshes. The MIKE FLOOD gives us the ability to evaluate the impacts of channel change on flow distribution both within channels and on the floodplain. We constructed and simulated three scenarios representing the baseline (i.e. no change to the current channel depth as in 2008), worsening (i.e. erosion keeps on going resulting deepened and built-up channels), and improved (through channel stabilizing etc.). The flow distribution and inundation extent under the three scenarios were compared for low, medium and high flows. The results showed that there were substantial differences in flooding patterns in terms of river flow distribution, flow breaking (into floodplain) locations, and inundation extents even for low flow conditions. However, the biggest changes were for medium flow. The study demonstrated that hydrodynamic models could be a useful tool in floodplain restoration through comparing the outcomes of alternative remediating works and predicting the outcomes of proposed works on wetland system hydrology and inundation patterns.

Keywords: Geomorphology, MIKE FLOOD, Inundation, Channel erosion, South Macquarie Marshes 


\section{INTRODUCTION}

The Macquarie Marshes (hereafter referred to as the Marshes) is large (over 220,000 ha) intermittently flooded wetland complex in the Murray-Darling Basin, Australia. The Marshes, includes some properties that are listed as internationally significant wetland under the Ramsar convention. Previous studies indicate that the Marshes have undergone ecological degradation under the influence of river regulation (Kingsford and Thomas 1995; Wen et al. 2012).

Emerging evidence from historical maps, aerial photographs, geomorphology and sedimentology indicate that channel migration (i.e. the formation new channels and abandonment of current creeks caused mainly by avulsion) also played an important role in flood distribution in the southern Marshes (Ralph and Hesse 2010). The combination of flow reduction and channel alteration contribute to the documented reorganization of floodplain biological assemblages. Therefore, in addition to environmental water allocation, infrastructure works and measures with the aim of restoration of stream physical condition and reconnection of floodplains might be necessary to maintain the existing ecological assets recognized in the Marshes.

Hydrodynamic models have been increasingly used in wetland restoration and floodplain management (Paudel et al., 2013). In New South Wales, 1D/2D coupled MIKE FLOOD models were built for major floodplains (Wen et al. 2013). With a relatively coarse resolution (90 to 100 meter grids), these models are primarily used to inform river system models for water sharing plans. For the assessment of the potential environmental works, finer scale model is needed. In this study, we built a MIKE FLOOD model with $30 \mathrm{~m}$ grid for the southern Marshes. By modifying the 1D cross-sections at critical locations, we investigated and presented the flood patterns for three scenarios under a range of flow condition. Our analysis highlighted that the impacts of channel alternation on flood patterns, and the importance of environmental infrastructures in wetland management.

\section{METHODS}

\subsection{The southern Macquarie Marshes}

The Marshes are located in the north west of within the lower Macquarie Catchment (Figure The area has a semi-arid climate with relatively rainfall, hot summers and cool winters. The average annual rainfall is approximately 447.4 (Quambone gauge).

The Marshes extend downstream from Marebone (NSW Office of Water Gauge 421088), which is situated $50 \mathrm{~km}$ north of the town of Warren (Figure 1). After this point, the floodplain transforms into a complex pattern of interconnected streams, lagoons, distributaries anabranching channels (Paijmans, 1981), and extends to the north a further $100 \mathrm{~km}$ until all the channels unite to form a single channel downstream of Carinda (Figure 1) which then into the Barwon River.

The Marshes sustain a wide range of forested wetlands, including river red gum (Eucalyptus camaldulensis), black box (E. largiflorens), coolabah (E. coolabah) and river cooba (Acacia stenophylla). There are also large areas of wet meadows including species such as common (Phragmites australis), water couch (Paspalum distichum), and Cumbungi (Typha sp). These vegetation communities provide important

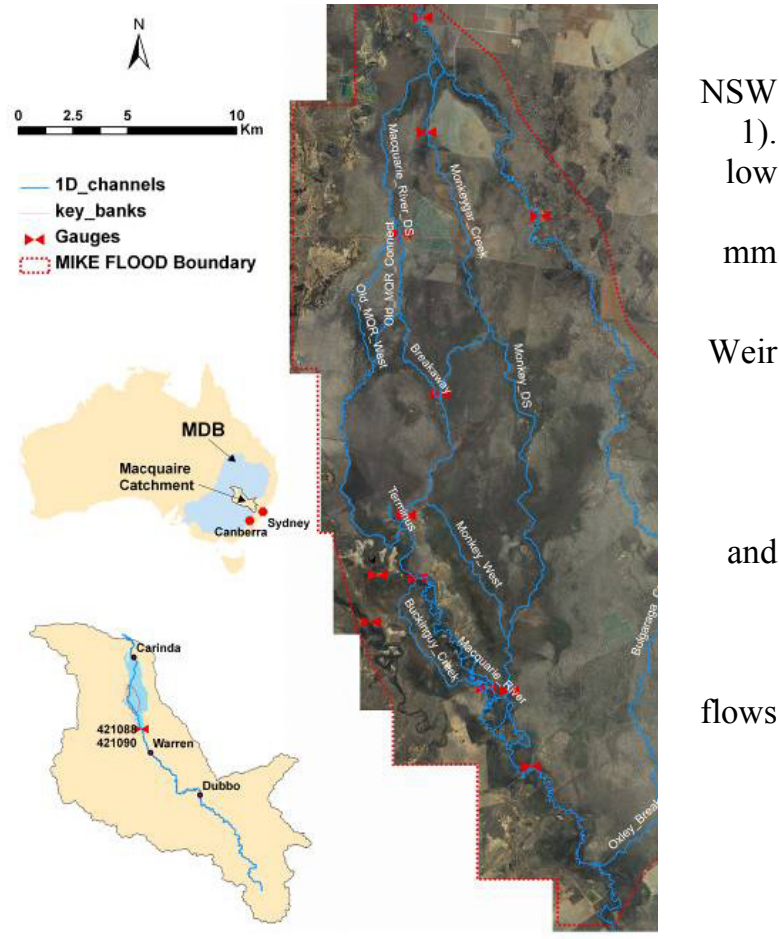

Figure 1 The boundary of southern Marshes MIKE FLOOD. Inserts show the location of Macquarie Catchment within Australia's Murray-Darling Basin habitats for many colonial waterbirds (Kingsford and Auld, 2005). Some properties within the Marshes, including the Macquarie Marshes Nature Reserve and two areas of private land have been internationally recognized as ecologically significant wetlands under the Ramsar Convention. 
It has been recognised that some parts of the Macquarie Marshes, such as the Ramsar site in southern portion of the Macquarie Marshes Nature Reserve, have experienced a decline in wetland vegetation communities in the last 50 years, largely due to water resource developments including river regulation, weirs, floodplain earthworks, and water diversion and abstraction for towns, agriculture and mining (Kingsford and Thomas 1995). These changes have modified the natural flow regime and contributed to changes in the inundation patterns of the Marshes (Wen et al. 2013).

The Marshes have experienced constant geomorphic changes, with more recent changes evident from historical and sedimentological records (Ralph 2008). These geomorphic modifications have also affected flooding patterns and total extent within the Marshes (Yonge and Hesse 2009).

\subsection{D/2D coupled MIKE FLOOD}

MIKE11 (1D river network) The 1D river network was developed based on the $1 \mathrm{~m}$ digital elevation model (DEM) derived from LiDAR Survey in 2008. The 1D river network represented the major rivers, creeks and irrigation canals in the south Marshes (a total of $347.9 \mathrm{~km}$ ). For each channel reach, at least three sections, at the start, middle and end of the channels, were digitized. Further sections were extracted where the channel has a sudden change in direction, shape and grade. Structures such as bridges, culverts, gates, were incorporated in the model along the channels. Specifications for the structures were obtained from the historical and ground surveys.

River hydrographs at the Macquarie River downstream of the Marebone Weir (421090) and the Marebone Break downstream of the Marebone Regulator (421088) (Figure 1) were the upstream 1D model boundaries. At the downstream, model boundaries discharge ratings table were automatically calculated by the model based on the channel cross-section of the Macquarie River, which represents river flow leaving the model area.

MIKE21 (2D floodplain) The floodplain was modelled using MIKE21. MIKE21 was performed at 30 grid cell resolution and 5 second time step in order to constrain the Courant number to be less than 1 (to ensure model stability) and to keep model run time within a practical range without losing the spatial details.
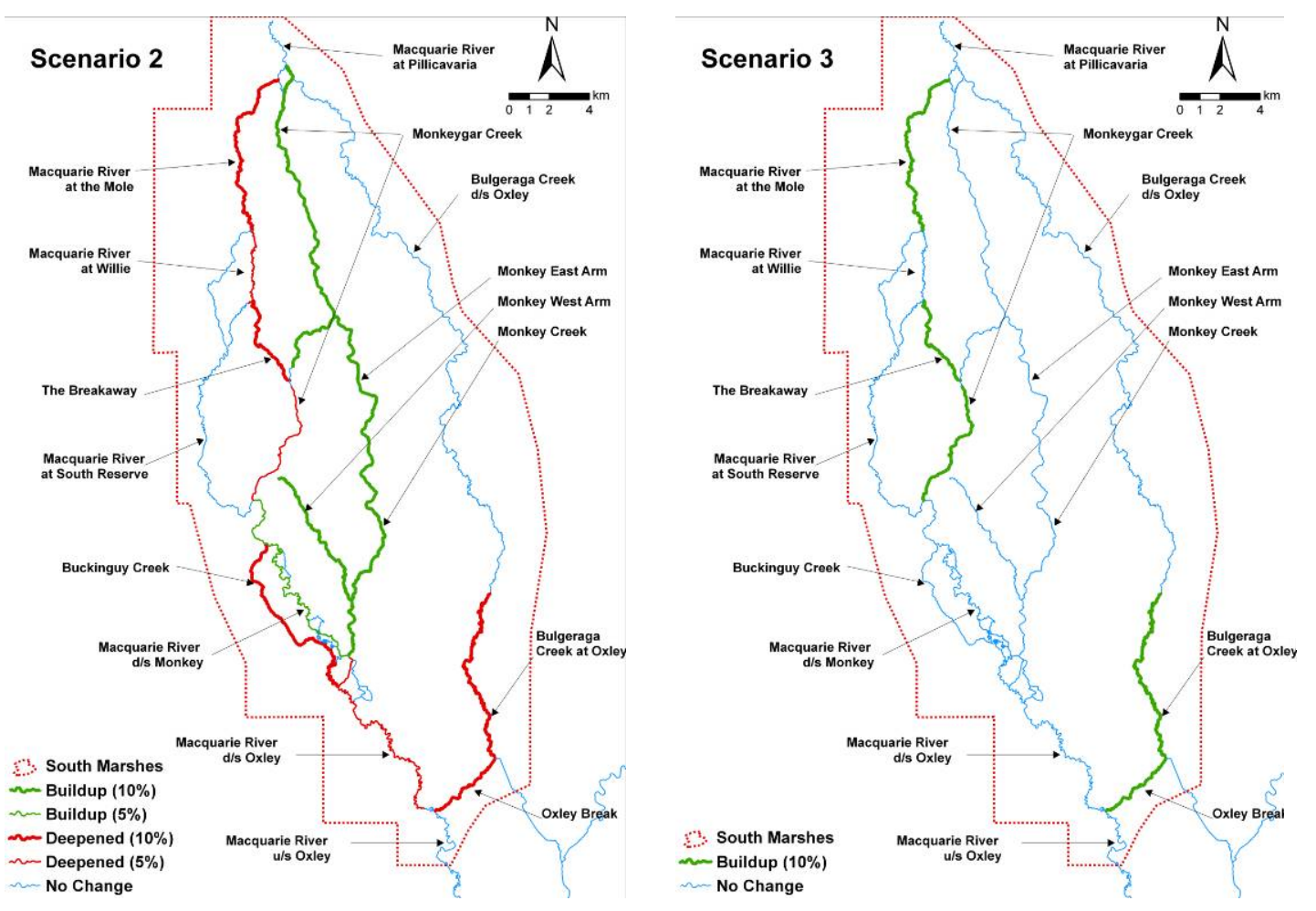

Figure 2 The potential channel alterations with no intervention (worsening, left) and with intervention (improving, right)

The hydraulic roughness of the floodplain varies depending on the vegetation type. Generally, the denser the vegetation the higher the roughness coefficients, as defined by Manning's ' $n$ '. The values selected for the 2D domain were based on the 2008 vegetation map developed by NSW Office of Environment and Heritage, which range from 0.02 to 0.07 . 
A representation of soil infiltration using the recently development MIKE21 HD -Infiltration and Leakage Module (DHI, 2009) was included in the initial model set up. Data on the infiltration rates (given as permeability or hydraulic conductivity) were initially sourced from soil survey (Jenkins and James, 2008).

MIKE FLOOD (1D/2D Linkages)

The 1D and 2D components of the model were coupled to provide flow exchange mechanisms between the two model domains. Lateral links $(30 \mathrm{~m})$ have been made between the 1D cross-sections and the $2 \mathrm{D}$ model grid cells. These links have been created by digitising the top-of-bank locations along the river channels using the LiDAR and ground survey data coupled with the aerial photography images.

Model calibration The MIKE Flood model has been calibrated against historical flow events. Data used for calibration included gauge records and remote sensing inundation extent (Thomas et al. 2012).

\subsection{Geomorphic Scenarios}

The flood behaviors under three geomorphic scenarios representing baseline (Scenario 1), deterioration (Scenario 2) and improvement (Scenario 3) were simulated by modifying the channel cross-sections (Figure 2). These scenarios represented future potential trajectories for existing stream incision, being without any intervention works (Scenario 2), the continuation of existing small-scale interventions in erosion-prone areas (Scenario 1) and scenario based on a larger-scale government funded suite of in-stream intervention works (Scenario 3).

Through geomorphic investigation in around the southern Marshes, Ralph (2008) identified channel breakdown

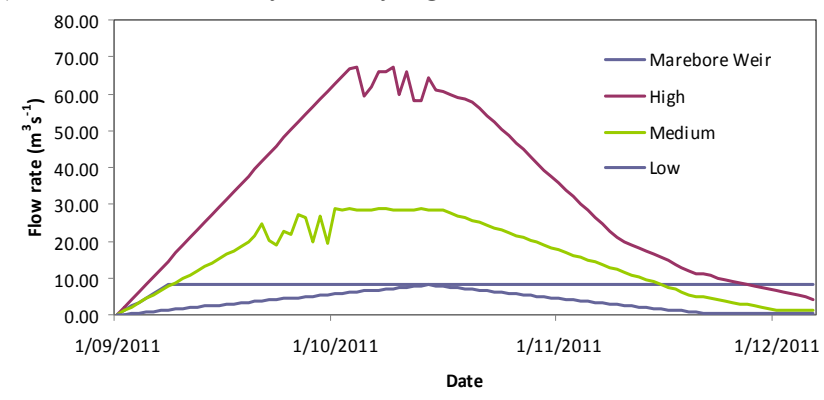

Figure 3 Artificial hydrographs as 1D boundary conditions under three flow conditions one

and

and avulsion as the two critical processes in the formation and evolution of the Marshes. Therefore, we considered that adjusting channel cross-section (i.e. building-up and deepening the channel bed) was the suitable way of modeling geomorphic change over time based on in-stream works to restore stream crosssections.

Each of the scenarios was modeled under low, medium and high flow conditions for 50 days using hypothetical hydrographs (Figure 3) as upstream boundary.

\section{RESULTS AND DISCUSSIONS}

\subsection{Model performance}

The comparison of simulated and remote sensed flood extent for the September - October 2011 flood event was shown in Figure 4. Table 1 shows the comparisons for various areas within south Marshes.

The MIKE FLOOD calibration results indicate broad trends of maximum inundation for the southern Marshes are replicated. However, reproduction of inundation extent for smaller areas (wetland-scale) is still relatively poor, especially for the Mundooie Floodplain, which seriously underestimated (Table 1). Along the Macquarie River, there are levees built, which were specified in the MIKE21 2D model. The levees stop overbank flows in simulation. However, in real situation, during the simulation period, the banks were breached at several
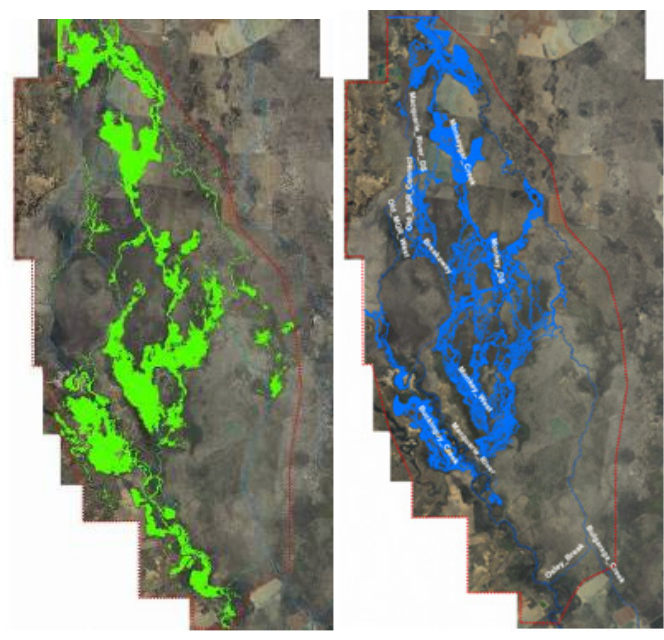

the

that

Figure 4 Comparison of mapped (left, Thomas et al. 2012) and simulated maximum inundation (right) for the southern Marshes during September - October 2011. these flow manipulations were not modelled. Therefore, the flood extent at this area was not accurately simulated. Another area, Macquarie River west of the South Reserve, was unacceptably overestimated. The inundation at this area is caused by the over flow from the Buckiinguy Swamp, which was linked with the 
Macquarie River via a weir located at the confluence of Buckiinguy Creek and the Macquarie River. Primary challenges to achieving accurate wetland-scale inundation simulation are based around the operation of floodplain and in-stream structures (e.g. regulators), inaccuracy in the LIDAR data around reedbeds and the small-scale complexity of channels and earthworks within some areas that cannot be sufficiently replicated with a $30 \mathrm{~m}$ spatial resolution.

Table 1 Comparison of total inundation extent (ha) for the remote sensing mapped and MIKE Flood simulated inundation area during the September to October 2011 flood event in the southern Marshes

\begin{tabular}{lccc}
\hline Wetlands within southern Macquarie Marshes & Simulated & Mapped & $\begin{array}{c}\text { Accuracy } \\
(\%)\end{array}$ \\
\hline Downstream of Monkey Swamp & 1105.8 & 1402.5 & 79 \\
Monkey Swamp & 885.2 & 1150.6 & 77 \\
Macquarie River west of Southern MMN Reserve & 632.9 & 243.9 & 259 \\
Southern Lagoons (between River and Bulgeraga Creek) & 3299.8 & 3262.7 & 101 \\
Buckiinguy Swamp & 968.5 & 1592.8 & 61 \\
Mundooie Floodplain & 40.3 & 866.9 & 5 \\
Floodplain along Bulgeraga Creek & 239.4 & 410.9 & 58 \\
Overall sub-system & 7171.9 & 8252.6 & 87 \\
\hline
\end{tabular}

Mapped flood extent data provided by Thomas et al 2012.

More generally, addressing the following issues could potentially improve the model greatly:

- obtaining more accurate ground surface levels in areas of dense aquatic vegetation (e.g. the reedbeds of Monkeygar Swamp and Buckiinguy Swamp);

- reducing the uncertainties in the stream gauging data

- calibrating of the model for flood recession; and

- higher resolution inundation extent mapping.

As a consequence of these model limitations, considerable caution must be exercised when interpreting results. Until the model can be better calibrated, it is recommended that any conclusions drawn from the model results relate only to broad changes in patterns of inundation and breakout timing, and are not made with respect to inundation extent, depth, or flows at specific locations.

\subsection{Scenarios Comparisons}

The modeling results showed that there were substantial differences in flooding patterns in terms of river flow distribution, flow breaking (onto floodplain) locations, and inundation extent under each flow condition. However, the biggest changes between scenarios were realized for medium flow. Due to the space limitations, we have only presented the results for medium flow events.

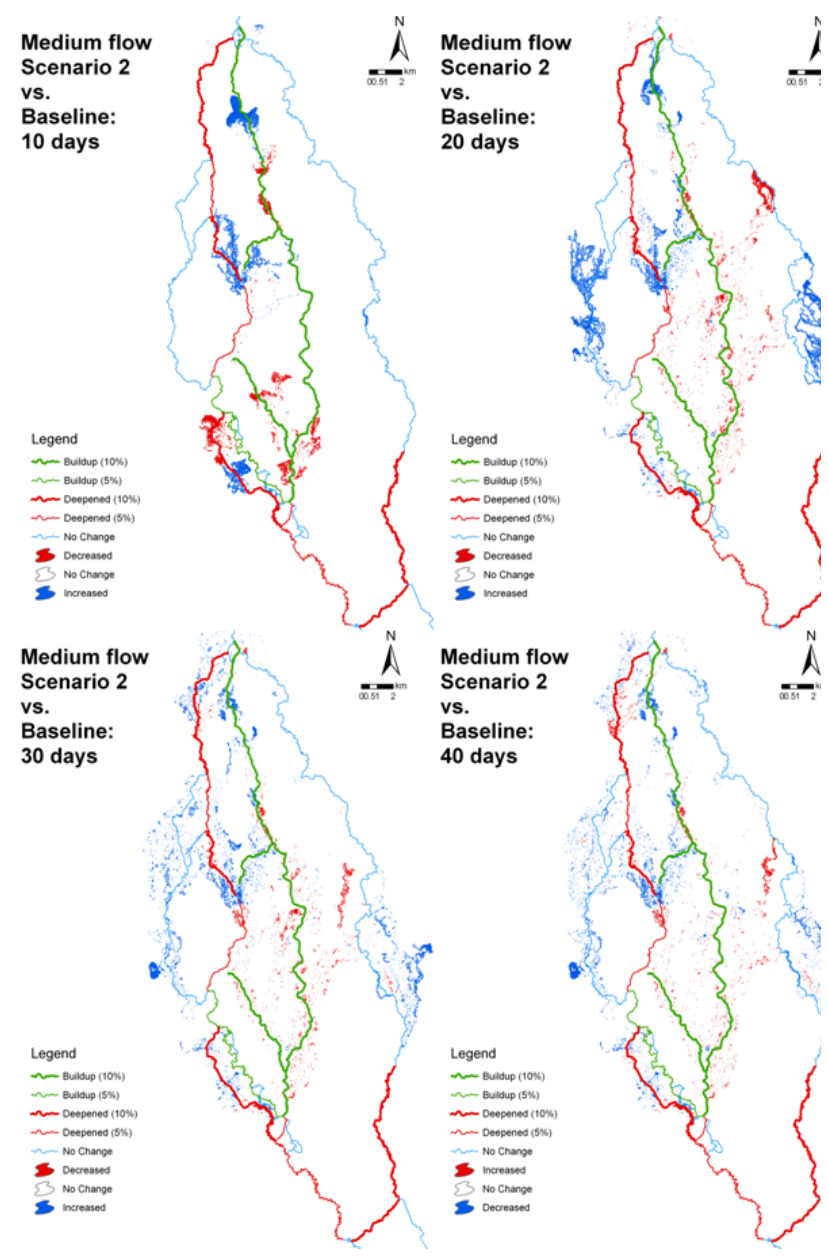

Figure 5 Changes in inundation patterns under medium flows for Scenario 1 (no intervention, deterioration) compared to baseline (Scenario2 minor interventions). 
Figure 5 shows the changes in inundation patterns relative to the baseline (Scenario 2) for the "worsening" scenario (Scenario 1, without intervention) under medium flow condition at 10-day intervals.

The figure indicates that inundation in the vicinity of the Breakaway and along Monkeygar Creek downstream of the Breakaway inundation occurred earlier in an event and was likely to increase in frequency as a result of channels becoming shallower, whilst inundation downstream of the Breakaway also seemed to occur earlier and with a likely increase in frequency as a result of greater volumes of water being distributed along this section of the system. The most notable change however appeared to be increases inundation of the floodplain of Bulgeraga Creek below Oxley. This was not apparent in the low flow case.

Decreases in inundation extent and frequency were less apparent in the medium inflow case. As with the low flow scenario, reductions in inundation extent appeared to occur in some areas of the Monkey Creek system for at 30 and 40 days into the event, indicating that these areas may experience some reduced inundation frequency despite channels becoming shallower. This may be attributable to more water flowing down the Buckiinguy system.

The comparison of inundation patterns between "improved" (Scenario 3) and baseline (Scenario 2) under medium flow conditions was presented in Figure 6 . Based on the simulation, inundation was greatly increased for the western part of the south Marshes. Reduction in inundation extent was also noticeable for areas along the Bulgeraga Creek as less flow went down the Oxley Break No. 3 due to modeled works to reduce channel cross-section. Under this "improved"

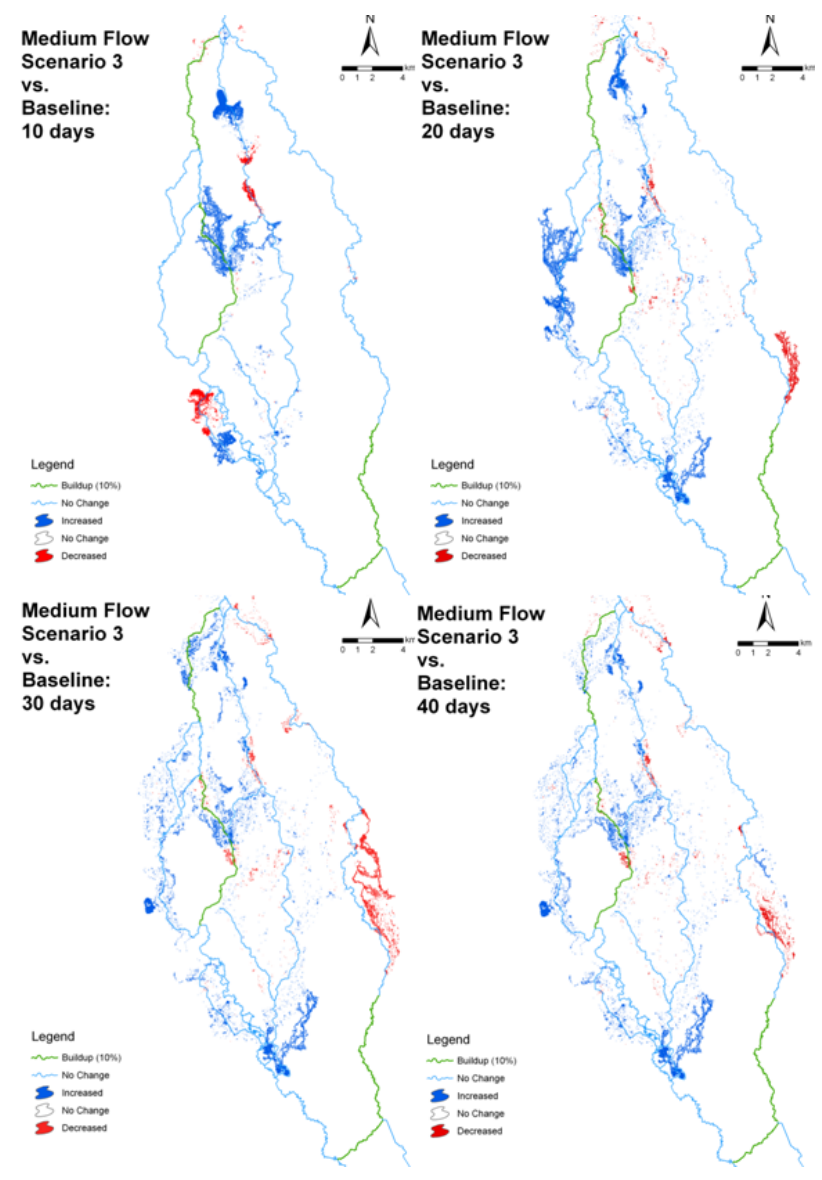

Figure 6 Comparison of inundation extent between baseline conditions (Scenario 2) and the modeled suite of intervention works (Scenario 3) under medium flows scenario, however, the inundation extent and frequency for the Southern Macquarie Marshes Nature Reserve, part of the Macquarie Marshes Ramsar site, was not improved.

\section{CONCLUSION}

The coupled 1D/2D hydrodynamic model showed changes in inundation related to simulated channel changes in the southern Macquarie Marshes. Further calibration of the model will lead to a better understanding of flow distributions in the system, as well as the frequency of inundation and cumulative downstream impacts. The model needs to be further tested with regards to hydrological responses to topographic change associated with different geomorphic conditions scenarios, since a combination of climate, hydrology, geomorphology and human impacts determine the ecological character of the Macquarie Marshes.

\section{REFERENCES}

DHI 2009. MIKE21 HD - Infiltration and Leakage Module. User Guide.

Jenkins, B. and L. James 2009. Report for Macquarie Marshes Wetlands Hydraulic Modelling: Volume 1 Background, Methodology and Results. Report for the NSW Rivers Environmental Restoration Program. Department of Environment and Climate Change NSW, Sydney. 
Jenkins K. M. and A. J. Boulton. 2007. Detecting impacts and setting restoration targets in arid-zone rivers: aquatic micro-invertebrate responses to reduced floodplain inundation. Journal of Applied Ecology 44 (4): $823-832$.

Kingsford, R.T. and Thomas, R.F. 1995. The Macquarie Marshes in arid Australia and their waterbirds: a 50 year history of decline. Environmental Management 19, 867-878.

Kingsford, R and K. Auld 2005. Waterbird breeding and environmental flow management in the Macquarie Marshes, arid Australia. River Research and Applications 21: 187-200.

Paijmans, K. 1981. The Macquarie Marshes of Inland Northern NSW, Australia. CSIRO Land Use Research. Technical Paper No. 41, 1-22.

Paudel, R., Grace, K. A., Galloway, S., Zamorano, M., and Jawitz, J. W. (2013). Effects of hydraulic resistance by vegetation on stage dynamics of a stormwater treatment wetland. Journal of Hydrology 484 (25): $74-85$

Ralph, T.J. 2008. Channel breakdown and floodplain wetland morphodynamics in the Macquarie Marshes, south-eastern Australia, PhD Thesis, Dept. of Physical Geography. Macquarie University, Sydney.

Ralph, T.J. and Hesse, P.P. 2010. Downstream hydrogeomorphic changes along the Macquarie River, southeastern Australia, leading to channel breakdown and floodplain wetlands. Geomorphology, 118(12), 48-64.

Ralph, T.J. Kobayashi, T., García, A., Hesse, P.P., Yonge, D., Bleakley, N. and Ingleton, T. 2011. Paleoecological responses to avulsion and floodplain evolution in a semiarid Australian freshwater wetland. Australian Journal of Earth Sciences, 58, 75-91.

Thomas, R.F., Kingsford, R.T., Lu, Y. and Hunter, S.J., 2011. Landsat mapping of annual inundation (19792006) of the Macquarie Marshes in semi-arid Australia. International Journal of Remote Sensing, 32, 4545-4569.

Wen Li, Xihua Yang, and Neil Saintilan (2012). Local climate determines the primary productivity and flooding creates heterogeneity in semi-arid floodplain ecosystem. Ecological Modelling (242): 116- 126.

Wen, L., Macdonald, R., Morrison, T. Hameed, T., Saintilan, N. and Ling, J. 2013. From hydrodynamic to hydrological modelling: investigating the long-term hydrological behaviours of key wetlands in Macquarie Marshes, a semi-arid lowland floodplain in Australia. Journal of Hydrology 500: 45-61.

Yonge, D. and Hesse, P.P. 2009. Geomorphic environments, drainage breakdown and channel and floodplain evolution on the Lower Macquarie River, central western New South Wales. Australian Journal of Earth Sciences, 56, s35-s53. 